\title{
LA EDIFICACIÓN EN MADERA EN EL SUR DE CHILE. HISTORIA DE UNA TRADICIÓN CULTURAL Y SU RECUPERACIÓN EN UN CASO: CASA PROCHELLE I
}

\author{
CONSTRUCTION ON WOOD IN THE SOUTH OF CHILE. THE HISTORY OF A CULTURAL TRADITION AND \\ THE HERITAGE RECOVERY APPLIED ON A CASE: HOUSE PROCHELLE I
}

\author{
SUSANA MUÑOZ LEBRETON
}

\begin{abstract}
RESUMEN
En el marco de la investigación bibliográfica acerca de la arquitectura patrimonial de la Región de los Ríos, proyecto de puesta en valor, organizado por la Dirección de Arquitectura del Ministerio de Obras Públicas, que tuvo por objetivo final, compilar y graficar todos los elementos de contenido patrimonial tangibles e intangibles, relacionados con el territorio, durante los años 2009-2010, se extrae parte de esa investigación que viene a dar luces sobre una secuencia de eventos asociativos, también llamado herencia cultural, sobre la edificación histórica de la zona sur de Chile, y que en general se disocia en los grupos culturales que ocuparon el territorio Mapuche-Williche, Español y el Alemán. Esta investigación pretende dar luces sobre esta evolución pluricultural de la arquitectura, basada en un ecosistema específico y adaptado a una dinámica terrestre como son los sismos y tsunamis. Este proceso lo veremos finalizado en una edificación declarada hoy Monumento Histórico Nacional en el marco de la edificación en madera. Sin dejar de destacar que la arquitectura lígnea es parte de una tradición constructiva de más de catorce mil años de evolución, y que hoy, en la primera decena del siglo XXI, está en un acelerado proceso de extinción.
\end{abstract}

\section{PALABRAS CLAVE}

Valdivia, edificación en madera, Casa Prochelle I.

\begin{abstract}
This investigation is framed on a bibliographical research about the heritage architecture of the Región de los Ríos, a valorization project, organized by the Dirección de Arquitectura of the Ministerio de Obras Públicas, which had as its final objective the compilation and charting of all the elements of tangible and intangible heritage content, related to the territory, during the years 2009 -2010. Part of this investigation gives light on a sequence of associative events, also called cultural heritage, on the historical construction in the south of Chile, and which in general it is dissociated with the other cultural groups which occupied the territory, Mapuche-Williche, Spanish and German. This research intends to give lights on this multicultural evolution of architecture, based on an specific ecosystem and adapted to a terrestrial dynamic such as earthquakes and tsunamis. This process ends with the declaration of this house as a National Historical Monument under the category of construction on wood. One must emphasize that the lignea architecture is part of a constructive tradition of forty thousand years of evolution, and which today, at the beginning of the XXI century, it is going through an accelerated process of extinction.
\end{abstract}




\section{Ocupación de territorio}

\section{De los originarios}

Antes de la llegada de los hispanos, el territorio contaba con una gran población nativa organizada en clanes, con distintas estructura socioeconómica y política, desarrollada en estrecha relación al área de asentamiento y posibilidades de producción.

Cordillera, pradera, borde costero, ya sea lacustre o marítimo, la topografía, el clima y los recursos determinarían, el sistema de alimentación, vestuario y la vivienda. Entre las características incuestionables y comunes para la ocupación de esta parte del territorio, es la cercanía a los cauces de agua corriente y navegables, elemento básico para el consumo, higiene y principalmente, como vía de comunicación.

La selva valdiviana es un bosque templado y templado-frío, rica en endemismos, siendo la única floresta templada lluviosa de esta parte del continente americano, con un piso de vegetación ${ }^{1}$ (Luebert y Pliscoff, 2004) que se caracteriza por presentar distintas formaciones de perennifolios, donde generalmente dominan los coihues, altos árboles del género Nothofagus, junto con numerosas dicotiledóneas arbóreas, coníferas, bambúseas, lianas, con una densa vegetación de epifitas, compuesta por musgos, líquenes, helechos y epifitas vasculares (Woda, Huber \& Dohrenbusch, 2006). Es el distrito más húmedo de la denominada provincia fitogeográfica subantártica, con suelos empapados de humedad, donde se encuentran ñadis, turberas y hualves, condición que determina que el asentamiento humano se haya realizado a partir de los márgenes fluviales, siendo las canoas monoxilas, llamadas Wampos ${ }^{2}$, piezas básicas del clan familiar (Lira, Díaz-Vaz \& Muñoz, 2013).

\footnotetext{
"Porque en las canoas traen los indios lo necesario, como es yerba, leña, y muchos mantenimientos; y no menos deleite en ver entrar a tantas canoas por aquellos ríos hasta llegar a las casas" (Mariño de Lobera, 1865 , p. 138).
}

La localización de estos era sobre en un terreno elevado donde se ubicaban las viviendas de forma dispersa, cada una contaba con una amplia área para el

1. "...espacios caracterizados por un conjunto de comunidades vegetales con una fisionomía y unas especies dominantes asociadas a un piso bioclimático específico" (p. 17).

2. Mapudungun, lengua de la etnias mapuche, huilliches y pehuenches, con algunas variaciones entre ellas $\mathrm{N}$ del a. desarrollo de un pequeño cultivo, denominado lof, el tamaño dependía del grupo familiar desarrollado con un patrón de residencia basado en la patrilocalidad, es decir, donde convivían todos o la mayoría de los descendientes masculinos del padre o jefe de familia, generando vínculos afectivos de cooperación y reciprocidad en concordancia con el desarrollo de las áreas de esparcimiento, para ceremonia y para la defensa, o para compartir en otras, como los Nguillatuwe y las canchas de chueca.

Hasta ahora la única referencia más detallada de un lof de nuestra zona de estudio corresponde a la descripción de la fundación de Valdivia escrita por un soldado español:

\footnotetext{
"descubrieron un gran pedazo de tierra algo alta como una loma casi toda cercada de aquel río donde tenían sus viviendas los naturales en razonables casas. Entraron los nuestros por esta loma y viéronla toda tan adornada de arboleda sembrada a mano que parecía un paraíso, así por la lindeza y orden con que están puestos los árboles, como por el río que va jirando en redondo por aquella loma. En medio de esta tierra estaba una larguísima carrera de cuatrocientos pasos por donde los indios jugaban a la chueca" (Mariño de Lobera, 1865, p. 138).
}

Este campo de chueca debe haber tenido un propósito anexo, ya que se sabe que las canchas tienen aproximadamente 200 metros de largo por 50 metros

3. Para el Consejo de Todas las Tierras, “... El lof, desde el punto de vista social, es un conjunto de familias que están asentadas en un espacio de tierras muy bien definido, a partir del cual se funda su identidad individual y colectiva. La identidad de cada integrante de un lof se funda en dos elementos básicos, el tuwun (lugar de origen) y el kupalme (tronco familiar). Estos elementos son determinantes para la pertenencia al lof. Estando claramente establecidos los dos elementos, una persona tiene definida su identidad social y territorial. La organización social y el lof estaban estructurados en base a las familias que lo constituían (...) El derecho a la adquisición, posesión y transmisión de las tierras no pasaba por la controversia social, ya que el lof era el espacio de convivencia, de unidad familiar, basado en la justicia y la reciprocidad..." Aukiñ Wallmapu ngulam, Consejo de Todas las Tierras, El Pueblo Mapuche y sus Derechos Fundamentales. Wallmapuche. Temuco, Chile, p 9-10. En un documento reciente elaborado por José Quidel y Víctor Caniullan, se define a los lof como unidades básicas fundamentales más pequeñas que los rehues. El lof estaría constituido por dos tipos de familias. En primer lugar está anümche, que son las familias que han estado asentadas en un determinado sitio desde tiempos inmemoriales. La otra categoría corresponde a akunche, y son aquellas familias que llegaron a asentarse en el territorio en un periodo posterior.

http://biblioteca.serindigena.org/libros_digitales/cvhynt/ v_i/1p/v1_pp_4_mapuche_c1_los_mapuche-2_html 
ancho, debe ser recta y en terreno plano de oriente a poniente. Describe el texto que alrededor de esta se encuentra el poblado y que sirvió, además, como punto central para proclamar a viva voz a la población la fundación de lo fundado. Sobre el poblado más al norte, actual San José de Mariquina, otro autor de 1557 hace mención señalando:

"Luego levantó Valdivia su campo, y perlongando la Cordillera Nevada, atravesando unos montes, vino a dar a un valle bien poblado llamado Marequina" (Góngora Marmolejo, 1862, p. 29).

De lo que podemos deducir, por la población mencionada, es que contaban con la misma estructura de organización urbana, además de las viviendas, las canchas de chueca, los campos de cultivo y los espacios no reconocidos o descritos por los hispanos como los sitios de Nguillatuwe y eltwe.

En relación a los cultivos, siglos más tarde el científico Philippi señaló sobre la población cercana al lago Ranco:

"Se ven no solamente trigales i papas, sino también maizales mui altos, arvejas, habas, fréjoles, betarragas, lechugas, claveles, amapolas, rosas, etc., principal- mente alrededor de las casas de indios que cultivan sus pequeños campos y señaladamente sus hortalizas con mucho más cuidado que los españoles que residen en este monte, i que se contentan con cuidar sus vacas" (Philippi, 1861, p. 15).

Condición que explicaría los asaltos que efectuaban a esta zona los soldados instalados en las unidades fortificadas de Quinquilca y Río Bueno.

Para la época del intento de conquista holandesa en 1643, se describe un área de desembarco y trueque de productos entre comunidades, definiendo para Valdivia el área para el mercado, espacio que debió estar presente en todos los centros de mayor asentamiento.

La especificidad mencionada anteriormente se vio alterada con la llegada del español, los clanes debieron adecuarse y elaborar sistemas para defender su subsistencia, además de la muerte en los combates, debieron enfrentar las pestes, esclavitud y los ataques psicológicos como la devastación de las casas y cosechas (Zapater, 1982) y el "trafico" de aguardiente, método usado hasta el siglo XX para diezmar las poblaciones de la precordillera.

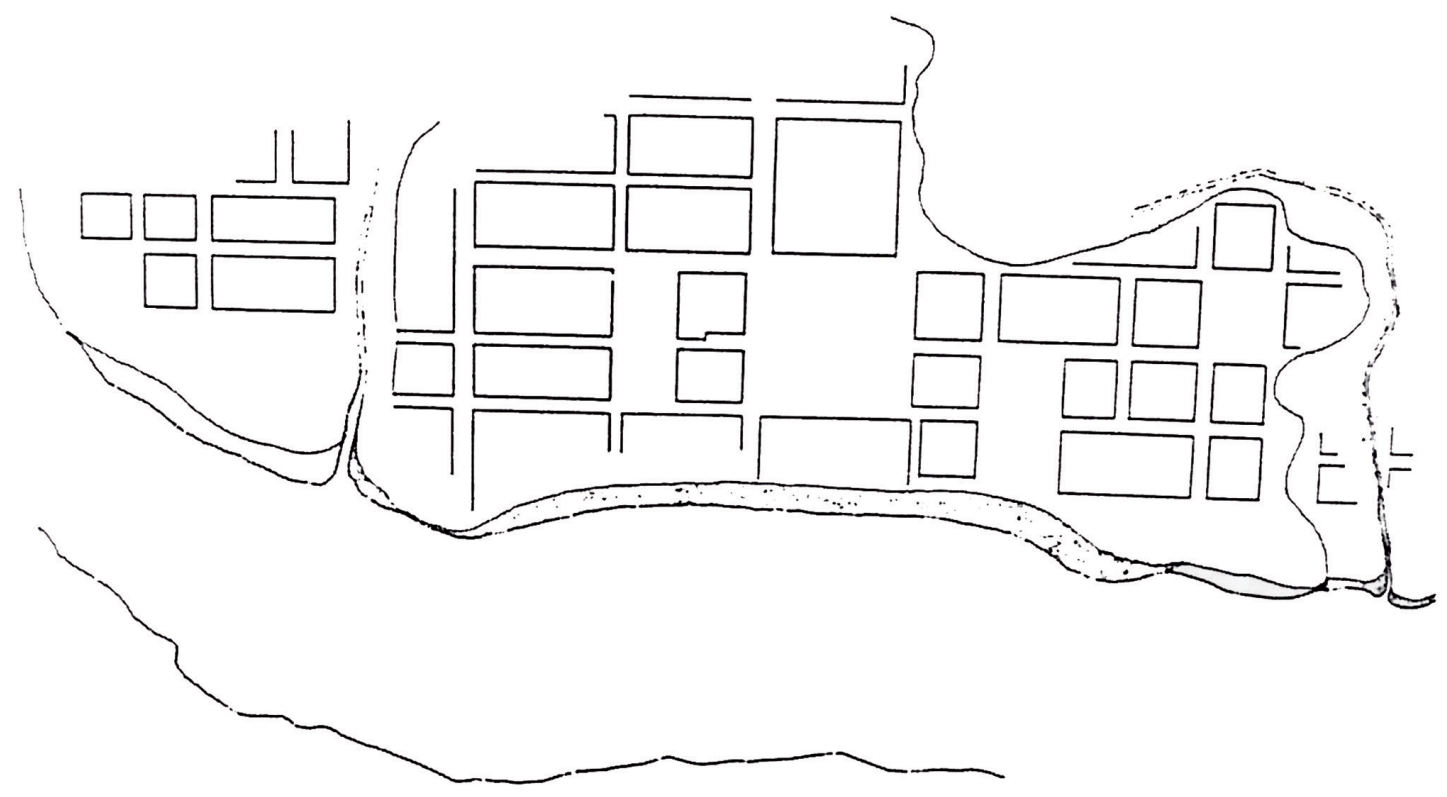


Estas modificaciones del espacio se realizaron en la medida de la incorporación del europeo al territorio, en el caso de las comunidades del Panguipulli, por ejemplo, el creciente interés por los campos de pastoreo y extracción de madera de las áreas lacustres, se repiten los mismos eventos a principio del siglo $\mathrm{XX}$, sobre una población indígena bastante más diezmada y menos organizada que en los siglos previos. Finalmente, hay asentamientos que terminaron por desaparecer con las pestes introducidas en el siglo XIX, Philippi mencionó dos casos:

"En veinte años la viruela destruyo, p.e., casi toda la reducción de Niebla, i hace pocos años que murió en la reducción de Trumao en pocos meses la séptima parte de los indios por pujos" (Philippi, 1861, p. 15).

Las comunidades que decidieron continuar con sus tradiciones ancestrales se trasladaron a áreas más inaccesibles como San Juan, Curiñanco, Riñinahue, Maihue, Mehuin, y muchos cruzaron la cordillera, donde han mantenido los elementos más significativos de su cultura, como son los espacios comunes, no así la vivienda, que fue uno de los primeros sistemas de transformación junto al vestuario. El cambio que iban naciendo al alero de las misiones donde las comunidades se veían obligadas a estar temporalmente en ellas, es descrito en 1845 por el intendente Salvador Sanfuentes:

\footnotetext{
"Mientras están en ellas, el misionero les proporciona su alimento, que es de trigo,...En recompensa los indios le trabajan al padre en las tares de siembra y cosecha, en formar cerros i demás ocurrencias de la misió. Las indias se ocupan también de hilar i en preparar la comida de los hombres..., .i al caer la tarde, se reúnen en grupos separados indio i las indias a rezar... Contra el sistema que acabo de delinear, oí varias objeciones desde mi llegada a esta provincia, siendo la principal..., de que a veces se les retenía en las misiones hasta un mes i más, distantes de sus familias i con quehaceres abandonados" (1925).
} dal de plaza Neuquén y aledaño por calle Janequeo al sur, el desagüe del humedal de calle Camilo Henríquez con Baquedano.

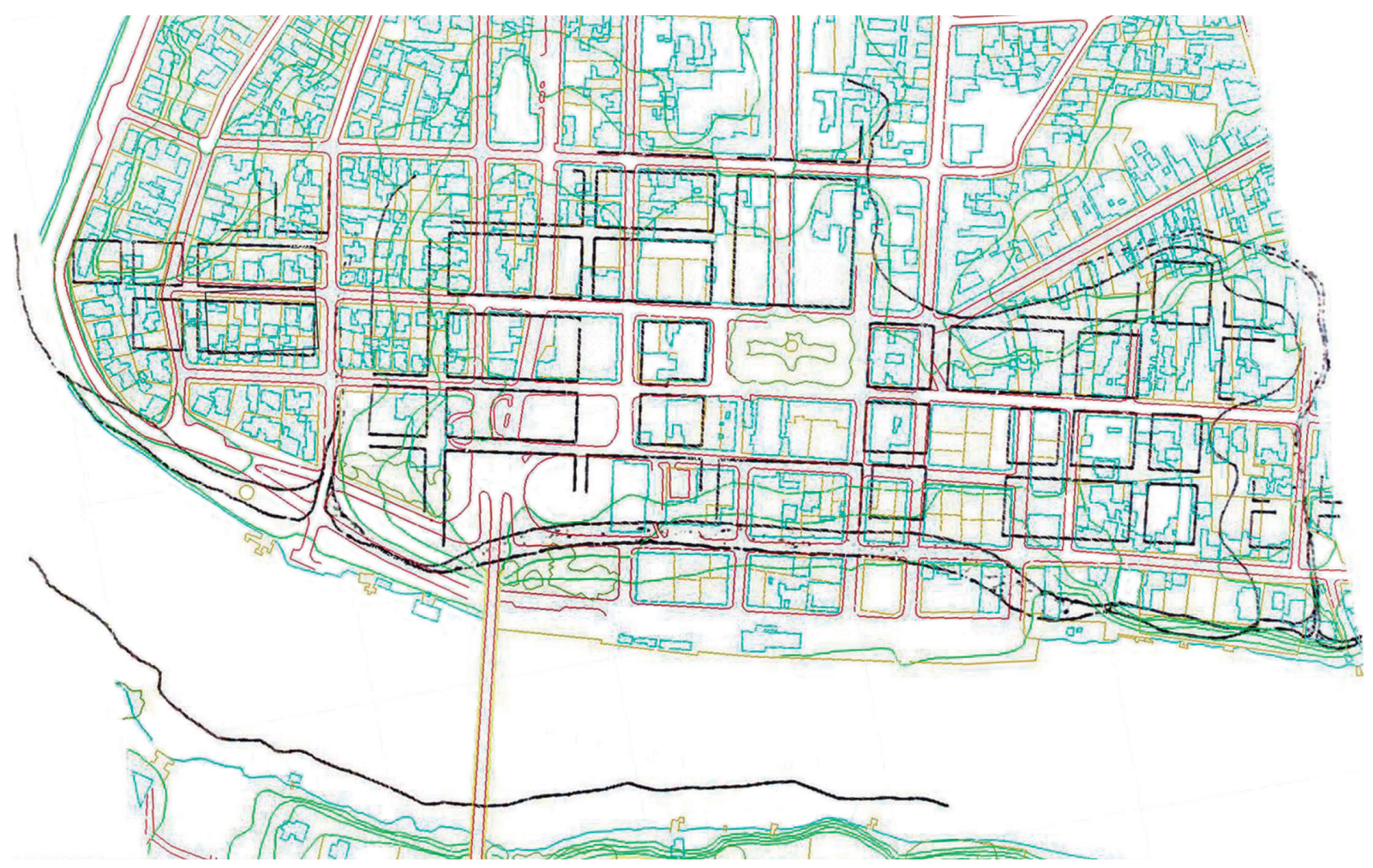


La organización social indígena tenía muy pocas posibilidades de subsistir, su sistema de ocupación del territorio era fuertemente criticado y declarado incivilizado, en 1846 el intendente Sanfuentes recomienda al Ministro del interior, sobre los indígenas así:

\begin{abstract}
"Ni creo la verdad que merezca grandes sacrificios el proyecto de fundar pueblos de indios. Todo el que conozca a fondo su carácter, no podrá menos que confesar que por sí solos ellos nunca harán progresos imperceptibles en la carrera de la civilización: cuando vieron hacer a sus padres lo respetan o imitan con el más ciego y obstinado fanatismo, como aborrecen i detestan cauto es contrario a sus usos transmitidos de jeneración en jeneración. El mal se encuentra originalmente en la raza, i mientras esta no se mejore cruzada i absorbida por otras, poco bueno hai que esperar del influjo de ajentes distintos" (1925).
\end{abstract}

Esta conclusión resultó ser un proyecto sistemático de los gobiernos sucesivos para ocupar el territorio de las poblaciones originarias, los estudios señalan que entre los años 1883 y 1891 fue el periodo de mayor número de colonos traídos a la frontera, entregándoseles tierras equivalentes a 60 mil hectáreas (Millanguir, 2007), recordando que dicho límite apolítico en la época estaba al norte del río Cruces.

La instalación de los misioneros capuchinos bávaros en ciertas localidades, como el Panguipulli, fue determinante para la denuncia de usurpación y asesinatos, con su sola presencia el colono del siglo XX debió controlar su codicia y abuso. El indígena usurpado o sometido a hijuelas recurrió a la migración o temporero empleándose como mano de obra en la construcción de la línea férrea (2007), cumpliéndose en lo sucesivo lo predicho por Sanfuentes, con la explotación masiva de la madera en todas las áreas lacustres del territorio de estudio, proceso que fue sistemático hasta la década del sesenta.

\section{De los hispanos y la incorporación de los germanos}

Al penetrar en territorio chileno, el español busca tierra fértil para garantizar su subsistencia, los asentamientos al sur del Mapocho siempre serán seleccionados por la proximidad de las comunidades indígenas, que además de abastecerlos de alimentos debían servir de mano de obra para las encomiendas. Existen testimonios tempranos referidos a la falta de habilidad del indígena para el cultivo ${ }^{4}$, refiriéndose

4. Descripción para la fundación de La Imperial, tomada como referencia. a los indios ubicados al sur del Mapocho hasta el río Maule, denominados Pomaucaes -lobos monteses- por los incas. Toda la crónica de Bibar expresa la búsqueda de comunidades nativas hábiles para el cultivos, las que eran saqueadas, no solo para la alimentación de la tropa, sino que también para cargar los navíos y enviarlos a las nuevas poblaciones hispanas, matando a los que se interponían, evidenciado así el temprano abandono de las viviendas por parte de los naturales. El procedimiento para la fundación de ciudades era el siguiente:

\footnotetext{
"Pasa por ella el río Cauten hondo y muy poderoso. Pasa otro pequeño río por un lado de la ciudad. Luego puso por obra de hacer un fuerte encima de la loma donde habia de ser la ciudad en que dejase la gente que le pareciese para volverse con quince o veinte hombres a la ciudad de La Concepción. Luego se entendió en hacer una cava y casas y en recoger comida para que quedasen apercibidos y que no les faltase. Esta es una loma que está sobre el río de Cauten” (1966).
}

Luego de las escaramuzas en la zona de Arauco, Bibar no vuelve a mencionarlas, continuando la marcha de reconocimiento hasta Villarrica para posteriormente dirigirse en diagonal hacia el mar hasta el valle de Mariquina, que por referencias sabían estaba muy poblado, del territorio de Valdivia dijo:

\begin{abstract}
"Esta ciudad de Valdivia está asentada en un llano; tiene algunas hoyas el río que pasa junto a ella, cerca la mitad de la ciudad. Está a dos leguas de la mar y los navíos entran hasta la ciudad por él. Hay alrededor de esta ciudad muy grandes montes y en sus términos. Esta la Villarica catorce leguas de ella. Es muy cenagosa toda esta tierra. Desde el río Toltén es montuosa, y estos árboles son robles y arrayanes y de ellos avellanos que tengo dicho. Hay gran cantidad de cañas macizas. Estos montes en alguna parte son ralos y en otras muy espesos...Hay buena madera para casas y aun para navíos" (1966).
\end{abstract}

Que el río protegiese el frente y costado de la ciudad, como señaló el cronista, y las ciénagas hacia tierra hacían del promontorio un área de defensa natural que definió la planta de la ciudad, ocupando casi completamente el borde habitable hasta el margen norte como lo muestra el plano levantado por la expedición holandesa en el año 1643, en el que se señalan los restos de la ciudad de 1599 compuestos en:

\footnotetext{
" 450 casas grandes, estaba dividida en varias calles, fuera de las callejuelas, y contaba con dos plazas de abasto; pero cuando la vimos, se hallaba completamente deso-
} 
lada, cubierta de arbustos y malezas, semejando más un desierto que una ciudad" (Brouwer, 1926, p. 111).

La superficie que presentaba la ciudad en 1599 no volvió a ser utilizada hasta 1850 con la llegada de la inmigración alemana. Durante las dos repoblaciones (1602-1604 y 1645), la comunidad civil y militar se replegó en una ciudad amurallada que abarcaba unas pocas cuadras, finalmente y en forma paulatina fueron ocupando las parcelaciones antiguas y las murallas reutilizadas en la pavimentación de las calles, aún cuando durante el siglo XVIII pasaron delineadores e ingenieros por la ciudad, los proyectos no se llevaron a cabo, todos los esfuerzos y recursos estaban centrados en el desarrollo de las fortalezas de la bahía, Valdivia se había transformado en una plaza militar para defensa del territorio del enemigo extranjero. Los terremotos de los años 1835 y 1837 derribaron todas las construcciones públicas y particulares.

El primer levantamiento de la ciudad del siglo XIX es elaborado por Bernardo Philippi en 1842, el plano es coincidente con lo que señalan los cronistas de la época, la ciudad había perdido traza regular, estabadesordenada, sucia y extremadamente pobre. Su hermano Rudolph llega diez años más tarde y escribe a Valdivia así:

\section{"Sabía por mi hermano que la ciudad era insignificante, mui atrasada así como toda la provincia, pero lo que vi me hizo una impresión más triste todavía. Había varias manzanas en que no existía más que una casa, así que las calles estaban con frecuencia marcando solo por cercos de tablas" (Philippi, 1900, p. 300).}

El comerciante Cesar Maas visitó la ciudad en 1847 coincidiendo con Philippi:

"La impresión que hace esta ciudad es muy mala. Su planta es irregular, sus casas de madera y las calles, solo en parte están pavimentadas con maderas y con piedras" (Maas, 1847, p. 34).

Paul Treutler llegó en 1859 y muestra que aún cuando el centro de la ciudad mantiene las mismas condiciones, la urbanización se extiende más allá de la muralla proyectada por Duce en 1780 que unía los torreones existentes:

"La plaza principal no se hallaba pavimentada y el suelo estaba formado, al igual que el de las calles, por una tierra gredosa rojiza,...Las casas situadas a los costados de la plaza, antiguas y bajas e inaparentes, pertenecen en su mayoría a antiguos vecinos. Sobre el costado occidental se eleva la iglesia construida por el ingeniero
Frick, de Berlín, con dos torres altas, y al lado se encontraba un recuerdo de tiempos antiguos el cabildo, construido de piedra y ladrillo, con la cárcel; en este edificio se reunía la Municipalidad" (Treutler, 1958, 286, 287).

"La calle más larga era la que se dirigía desde la plaza principal hacia el este; bajaba bastante abruptamente y también en esta parte se elevaba una antigua torre sobre las ruinas de las murallas de la ciudad. Comenzaba en seguida un camino bastante bueno, construido por los ingenieros alemanes Frick, Lagrèze y Harnecker, que conducía hasta el caserío de Futa, situado a cuatro leguas al interior. A lo largo de él había una fila de casas y posesiones rurales, como también los cementerios católico y protestante, que eran muy bonitos y finalmente una quinta, donde se encontraba un salón de cerveza, con billar y cancha de palitroque muy frecuentado" (Treutler, 1958, pp. 286-287).

En este periodo, aún se consideraba que el territorio indígena comenzaba en el Cruces, punto que esta definido por el castillo del mismo nombre, que en este momento histórico se encuentra en ruinas, pronto el muelle del fuerte donde llegan los botes a remos ayudados por las mareas, se traslada más al sur llevando en vaporcitos a la gente que comienza a ocupar paulatinamente las cuencas de los lagos Panguipilli, Coñaripe y Villarrica, para 1900 el periodista José Alfonso relataba:

"Cerca de la una de la tarde, llegábamos al puerto de San José, primera ciudad que encontrábamos después de haber salido de Temuco. Ahí almorzamos i, después de un último y apresurado galope para alcanzar el vapor que nos habria de conducir a Valdivia, llegábamos, a las cuatro de la tarde, al puerto fluvial de Cullinhue, i ahí nos dieron la mala nueva de que el vaporcito ya habia partido. Pudimos sin embargo, fletar uno especial" (1900).

La población indígena y mestiza del valle de Mariquina era muy participativa de la misión capuchina instalada más al norte, los padres misioneros se encargaban de la educación de los niños, el bautizo de la población y la atención de las enfermedades que las machis no podían curar. El primer plano que se conserva corresponde a un boceto elaborado por Bernardo Philippi, que muestra:

\footnotetext{
"Una gran plaza, pero ella ofrecía un aspecto desierto y triste debido a que la población no había aumentado mucho. En el costado sur se encontraba la misión y la iglesia; en el poniente, la escuela; en el del levante, la casa del juez Moreno, la cárcel y una gran bodega; y en el septentrional, dos pequeñas chozas. El edificio de la misión, la iglesia y todas la demás casas estaban construídas de madera y la plaza de hallaba cubierta de pas-
} 
to, el que era consumido por caballos vacunos y ovejunos. Por el occidente y el sur, el lugar estaba rodeado de bosques. Por el oriente lo limitaba el río, en cuya orilla opuesta había varias pequeñas casas, rodeadas por campos cultivados y bosquecillos de manzanos y hacia el norte los terreno se encontraban limpios y cultivados a lo largo de un buen trecho" (Philippi, 1900).

En Corral la población se ubicaba bordeando la playa principal que sube en dirección al castillo de San Sebastian de la Cruz:

\footnotetext{
"se componía de pocos casas formando una sola calle; no existía un hotel ni cosa parecida a tal, ni tenía panadero; cada vecino hacia el pan necesario en su casa i era a veces difícil obtener pan i sino preguntando de casa en casa si sobraba pan para vender se conseguía. No había comunicación regular con Valdivia; pero algunos vecinos tenia botes para la pesca i para el viaje a la ciudad" (Philippi, 1900).
}

En 1852, en La Unión existía un almacén poco abastecido (Philippi, 1900), para 1860 (Philippi, 1861) su aspecto urbano había mejorado, de unas cuantas chozas a treinta casas de buena fábrica.

En quince años la traza urbana de las ciudades de Valdivia, La Unión y Río Bueno habían cambiado considerablemente, el número de calles en Valdivia había aumentado a diecinueve, seguían siendo de barro, posiblemente algunas conservaran las basas transversales para el tránsito de carretas, y las veredas de piedra laja. El número de viviendas habían aumentado a 375, y entre otros adelantos se había instalado alumbrado público compuesto por 40 faroles a parafina (Tornedo, 1872).

Los clanes familiares de poder económico instalados en los bordes fluviales comienzan rápidamente a expandir sus propiedades hacia el interior cordillerano, instalando grandes fundos donde la explotación principal era la madera, seguido de la leche y los subproductos de esta. En esta época, la construcción está en su máxima actividad, los temporeros constructores se trasladan desde Chiloé para la construcción de viviendas puentes, edificios y embarcaciones, la población obrera en Valdivia era incalculable, quedando en evidencia en el incendio que afectó al centro de ciudad en 1909, y los numerosos conventillos existentes. Al año siguiente se constituye la regulación Municipal (Almonacid, 2000). Los barrios de Las Animas, Barrios Bajos, Miraflores, Teja Sur, Estación Ferroviaria crecen hasta el año treinta con personas que se trasladan de los sectores rurales de San José de la Mariquina, Los Lagos, La Unión, etc. Extensiones que nacieron para ampliar el funcionamiento de fábricas como la de calzados Rudloff, Hoffmann, Cervecerías Unidas y otras que aumentaron su dotación durante este periodo.

\section{La vivienda}

La vivienda tradicional es de planta circular, ovalada o semi-rectangular, las más amplias correspondían al lonko del lof, y eran construidas a partir de pie derechos plantados a suelo, el área central era más elevada y perforada a modo de cañón.

Usaban para la estructura, roble pellín (Nothofagus oblicua), luma (Amomyrtus luma) y laurel (Laurelia sempervirens), los postes son ubicados espaciados en las zonas de costa y valle central, usando la quila para entramar y fibra vegetal para amarre y completar la cubierta. La fibra es de especies acuáticas ${ }^{5}$, denominada küna o paja ratonera ${ }^{6}$, adecuada para el escurrimiento del agua lluvia ${ }^{7}$.

El uso de especies es diverso y depende de la existencia en el territorio, por ejemplo, para las zonas de cuencas lacustres o clima cordillera se usa el coirón, en la áreas húmedas marítimas el Scirpus californicus, (C.A Mey) Steud ${ }^{8}$ denominado junco, paja, totora o tromé; el Phragmites Australis (C.A.) Trin. Ex Steud $^{9}$, caña, carrizo o paja ambas nativas, usadas para techar ${ }^{10}$; la enredadera boqui fuco berberidopcis corallina para amarras. Hacia la cordillera la empalizada estacada a suelo es elaborada con troncos rebajados, con la misma técnica, instalados a modo de empalizada continua, lo mismo para la cubierta donde se disponen las piezas convexas traspuestas

5. Macrófitos acuáticos. Hauenstein y Falcon. Clave para la determinación de las plantas acuáticas y palustres del santuario de la Naturaleza Carlos Anwandter (Valdivia, Chile) p. 41 http:// www.ceachile.cl/publicaciones/2001.\%20Plantas\%20acuaticas\%20Hauenstein\%20.pdf. 05/10/09.

6. Designación hispana, ya que al quemarse la vivienda veían huir la gran cantidad de ratones que podían subsistir. Ref. oral Leonor Manquel.

7. Valdivia y sus alrededores tiene la más alta pluviometría del país, en promedio 2000 milímetros de agua caída anual.

8. Nombre científico: Cyperaceae.

9. Nombre científico: Poaceae.

10. En otros lugares también se usa para la construcción de viviendas, celosías, vallas, flechas de los indios, y para llevar a tejer esteras y redes. Recuperado el 27 de abril de 2009, desde www.hort.purdue.edu/newcrop/duke_energy/Phragmites_ australis.html 


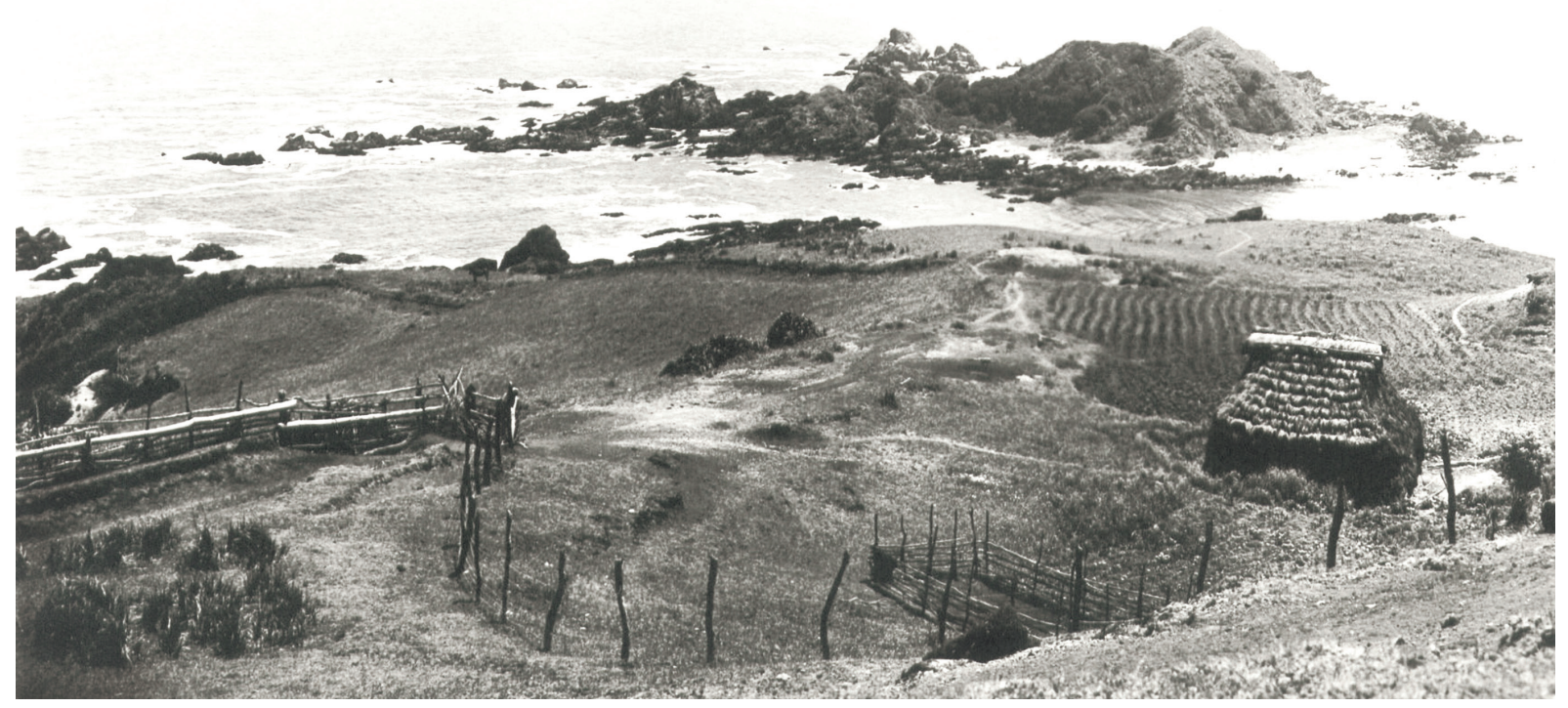

para contener las nevadas. Las edificaciones podían tener varias puertas dependiendo del tamaño, el acceso principal siempre orientado al este.

La población instalada en las misiones vivían en galpones destinados para el sueño según señalaba Sanfuentes, separados hombres de mujeres.

Después de cuarenta y cuatro años de abandono ${ }^{11}$, los holandeses grafican ${ }^{12}$ elevaciones de las ruinas diferenciando claramente las construcciones mampostería -piedra o ladrillo- de las de madera, mostrándonos el sistema de edificación al referirse a $c a$ sas grandes.

La tradición de construcción en piedra y ladrillo es reemplazada, durante los procesos de repoblación de las ciudades, por la madera, la tecnología de la cantería se pierde, usándose solo en las fortalezas, y en edi-

11. Durante el intento de repoblación en 1602 la cuidad no es ocupada, las 1,520 personas se instalan hacia el sur creando una ciudadela amurallada (n. del a.).

12. Plano holandés de 1643 , Biblioteca Universidad de Göttingen en Guarda, 1990, 1993, 2001, 2009. ficios públicos el ladrillo; todos son proyectados por ingenieros quienes transportan a sus obreros especialistas, y para la construcción de naves, irlandeses (Mackenna, 1840). La tecnología de madera manejada por los nativos es utilizada con los recursos limitados que tuvo el hispano durante todo el periodo de repoblación. Este recurso en extremo abundante se veía, además de ilimitado, desechable por lo que una choza podía rápidamente ser remplazada por otra, otro aspecto era la desidia, la colonia española se consideraba descendiente de hidalgos, condición cultural del español en general (Irving, 1832), no estaba destinado a esfuerzos como el trabajo y al estudio (Anwandter, 2006), por lo que era usual que optaran por la carrera militar o eclesiástica.

Con la llegada de colonos y viajeros alemanes tenemos una visión más clara del sistema constructivo de este periodo. Vemos que esta forma de edificación parcialmente modificada es usada por la población mestiza e indígena que se instalan en la ciudad, siendo objeto de preocupación por parte del doctor Schneider, que en 1853 estudia la salud de la población valdiviana, describiendo las viviendas como sigue: 


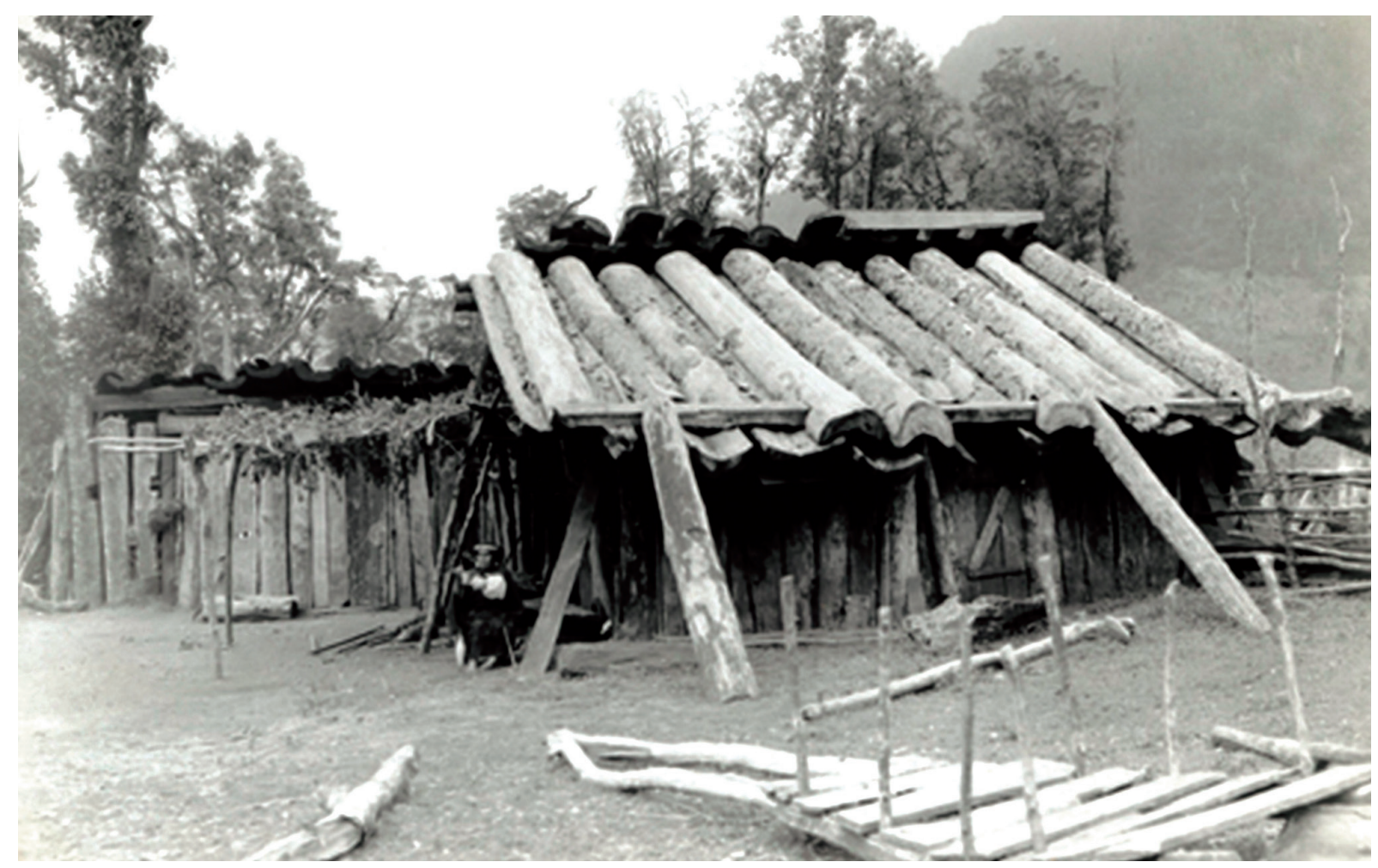

"Postes colocados en hilera, que dejan entre si espacios considerables forman las habitaciones de la mayoría de los pobres, careciendo muchas de puertas i casi todas de buenas ventanas de vidrios, los que suplen algunas veces pedazos de tocuyos; los techos son mui defectuosos, i las paredes como los techos dan libre paso no solamente al aire, sino también a las aguas, que entran mui a menudo. En medio de un rancho como el que pinto, vemos encendido un fuego cuyo humo llena toda la atmosfera" (Schneider, 1853).

Schneider no mencionó la materialidad del techo, siendo común la paja, aun cuando no se descarta el uso de tablas, ya que en la época constituía una de las principales fuentes de subsistencia de la población obrera, como menciona Treutler ${ }^{13}$, que la usaba como moneda para la adquisición de insumos bási-
Figura 3 (página anterior)

Ruca en borde costero marítimo, el mismo sistema se usa en los valles.

Fuente: Colección fotográfica Dirección Museológica Universidad Austral de Chile.

Figura 4

Ruca del área cordillerana.

Fuente: Colección fotográfica Dirección Museológica Universidad Austral de Chile.

13. El peón ganaba en Valdivia cuatro reales al día (dos marcos), pero como la mayoría de ellos son madereros y trabajan a tratos, ganaban por lo general seis reales. El pago se hacía semanalmente, pero no en Valdivia, sino en los bosques donde estaban ocupados, y no en dinero, sino en tablas de alerce. De este modo, se veía todos los sábados a centenares de hombres, mujeres y niños, que salían de los bosques con tablas en la cabeza, para dirigirse a Valdivia y pagar con ellas sus compras en el comercio (p. 292). 
cos. La forma de las viviendas, era de un agua para los más pobres y dos para las personas de más recursos, modificando el tiro para la eliminación del humo del fogón central que tiene el interior de la ruca, cuando Schneider señaló que la vivienda está inundada en humo, es una condición que no presenta una ruca.

A su llegada, Carlos Anwandter apuntó:

\begin{abstract}
"Las casas son completamente de madera de un solo piso, con tejados de tejuela, en su mayoría tan estropeados que cuando llueve en abundancia dejan penetrar el agua. La paredes están formadas casi siempre por fuertes vigas verticales, muy juntas unas a otras, que van clavadas a tierra y por dentro van revestidas de tablas. Las ventanas en su mayoría tienen un enrejado de madera sin cristales y, como las paredes tampoco son muy compactas, dejan pasar bastante corriente. Las grietas se tapan durante la época de lluvias con musgo" (2006).
\end{abstract}

Mientras Philippi consideró que:

\begin{abstract}
"Casi todas las casas estaban construidas del mismo modo que las de, los araucanos. Troncos de roble partidos, a los que el hacha había dado una forma cuadrada, formaban las murallas; no tenían cimiento, estaban enterradas en la tierra en zanjones de un metro de profundidad. El piso de las piezas era formado de tablones labrados con el hacha; el cielo raso era de tocuyo; las ventanas estaban cerradas por una reja cruzada de madera, contra la cual se clavaba tocuyo cuando el viento empujaba la lluvia para adentro; en el hueco de las ventanas había un estrado, en el cual las señoras de la casa se sentaban con los pies cruzados como en el Oriente; las paredes de las piezas estaban, en las casas mejores, entabladas; los muebles mui primitivos; sofaes, sillones, sillas de junco eran objetos raros, de lujo" (1900).
\end{abstract}

La casa de don Ventura de la Fuente, administrador de la Aduana, mencionada por todos los cronistas de la época como una de las mejores y más grandes de Valdivia (Maas, 1847), acogía a todo extranjero ilustre ante la falta de alojamiento en la ciudad, permitiéndonos inferir que la limitante para mejorar la construcción era el financiamiento, ya que De la Fuente debió haber trasladado a la ciudad, temporalmente, carpinteros para la edificación de su mansión de elegancia europea (Guarda, 2001). Ya que durante este periodo, quienes con oficio habían intentado trasladarse a la ciudad se marchaban muy pronto debido a la pobreza de la población.

Tornedo señaló:

"Desde 1850, los industriales extranjeros que emigraron a la provincia, hicieron adoptar un nuevo método de construcción i aunque los edificios construidos des- de entonces son también de madera, presentan un aspecto elegante i risueño: en el techo se emplea una teja especial en forma triangular y el fierro galvanizado en vez del alerce" (1872).

En el transcurso de esta época y la primera mitad del siglo XX se van adoptando técnicas constructivas incorporadas por la inmigración alemana, se aísla la madera de la humedad del suelo. En el área de costa del Pacífico se hace con hiladas de piedra laja o pizarra, seleccionadas de tamaño regular, sin cantear y sin mortero, trabándolas por peso. Los verticales trabajados a azuela que forman los muros se transforman en pie derechos aserrados, apareciendo además las soleras, la cadeneta, el revestimiento exterior e interior, el externo, compuesto por tablas de alerce horizontales traslapadas, derivación del traslapo de los juncos en primera instancia, realizado luego con tablas de alerce rajadas a modo de tejuelas; y en el interior por tablones de laurel cubiertos con arpillera, papel rústico y papel decorativo, llegando a este proceso más refinado a partir de 1860 con tablones para traslapo, forma más rebajada hacia el remate de contacto y en el borde exterior un acanalado doble de medio rondo más rebajando, este último para el escurrimiento de agua lluvia.

La abundancia del alerce permitió también la factura de un falso ladrillo elaborado sobre paneles de esta madera que perfectamente unidos y pintados daba la apariencia de una fachada perfectamente enladrillada. El volumen es simple con techo de dos aguas y altillo en las viviendas más pudientes pasando a ser la edificación típica de la costa.

Hacia el interior en la zona lacustre y cordillerana las bases son basas de roble pellín (Nothofagus oblicua), se mantiene la forma del techo, se elimina el altillo incorporando áreas anexas o corredores porticados simples, que sirven para airear carne, cueros y/o bodega.

Con la incorporación de mano de obra calificada, la ciudad comienza a crecer en altura, a aparecer las viviendas de dos pisos, algunas de ellas conservan el volumen simple con techo de dos aguas, muchas incorporan la mansarda habitable, las más exóticas con volúmenes salientes. No todos los inmigrantes gozan de la comodidad habitacional, al parecer, muchos de los que no formaron parte del círculo industrial de la ciudad tuvieron que instalarse en habitaciones muy similares a las usadas por la po- 


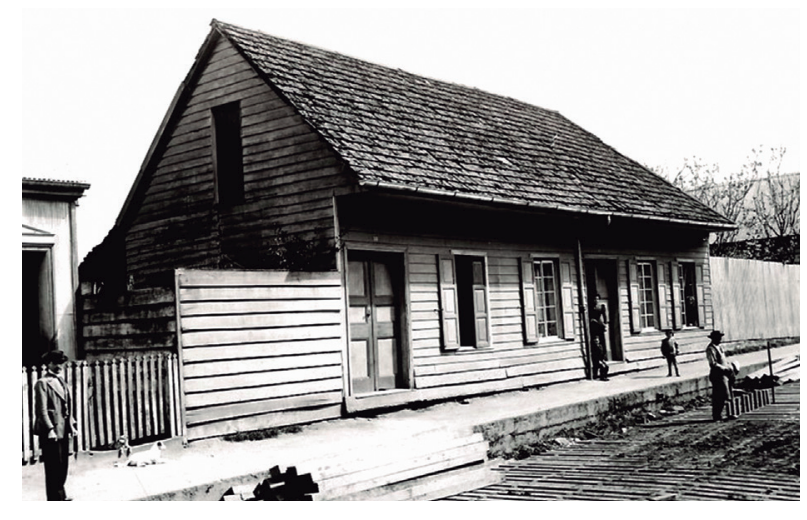

Figura 5

Dotación de alcantarillado y alumbrado público, se registra la modernización estética de la fachada de la casa. Fuente: Archivo fotográfico Dirección Museológica Universidad Austral de Chile.

blación indígena y mestiza, como se señala en el documento inédito de Helmut Ziegele,

\begin{abstract}
"Desde ahí se trasladaron a una modesta casa en el sector de Huachocopihue donde hoy se encuentra el Hospital Regional, cerca de los Uribe, Geywitz, Spröhle y Ribbeck. Esta era techada con hojas de chupón y cunquillos. Aquí nació la tía Elisa Ebner”14 (2002).
\end{abstract}

Las viviendas fueron acondicionadas según el desarrollo urbanístico de la ciudad, en las imágenes anteriores se observa la misma casa, que además de mejorar la fachada, el sistema de ventilación, modernizar ventanas, incorpora canaletas y bajadas de agua que drenan a la calle por los nuevos ductos de agua lluvia de la ciudad, e incorpora elementos decorativos de origen alemán y pintura en la fachada principal, siendo su propietario de ascendencia española, mostrándonos que mixtura dependía de la modernización y de los recursos.

Hasta aproximadamente 1930, es un periodo vasto en el que conviven las rucas, chozas, casas de madera con cubierta de tejuela de alerce que paulatinamente, se transforma el hierro galvanizado, y los más acaudalados levantaban pequeñas mansiones de la que abordaremos un caso.

14. Se refiere a Elisa Ziegele casada con Juan Ebner, maestro cervecero propietario de la cervecería del mismo nombre ubicada en calle Carlos Anwandter.

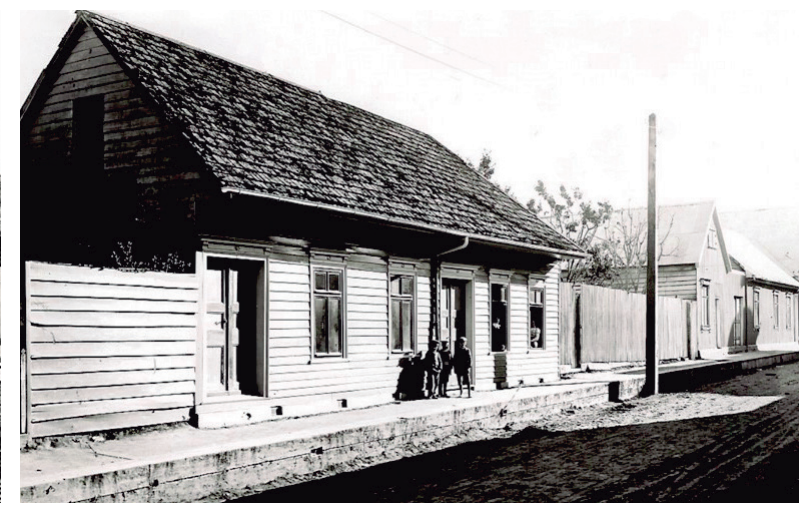

\section{Casa Prochelle I Monumento Histórico Nacional DS N 918}

Con la llegada de la colonia alemana progresivamente, a partir del año 1850 , se produce un cambio radical en el paisaje de la ciudad. Para la instalación de los primeros inmigrantes alemanes patrocinados por el gobierno de Chile, se subdivide la isla Teja, este terreno, ubicado al poniente del centro de la ciudad, tiene una superficie de 563,02 hectáreas, siendo habitables 150,9. El territorio se subdividió en 199 hijuelas de las que tenían derecho a compra, dos por cada hombre mayor de edad.

La mansión original estaba sobre una de las dos terrazas de mayor uso histórico para la ciudad, donde se instalarían posteriormente los actuales monumentos históricos casa Anwandter y las casas Prochelle, estas riberas más elevadas y terraplenadas contaban con pequeñas playas de arena, ideales para el atraque y desembarco.

El pionero de las curtidurías en la ciudad de Valdivia fue el alemán Hermann Schülke, fue quien adquirió el terreno, equivalente a la subdivisión posterior de diez cuadras, a la Ilustre Municipalidad de Valdivia. El sitio de 900 por 2,250 pies, no presenta las subdivisiones en pequeñas hijuelas como el resto de la isla y su nombre aparece en la escritura de venta de 1850 como excluyente de la que se estaba realizando, por 
lo que debemos suponer que este gran lote fue vendido con anterioridad, y la llegada de este colono debió ser a través del puerto de Valparaíso, al menos uno o dos años antes de esta fecha. La superficie abarcaba desde el actual Parque Prochelle hasta el actual club de deporte acuático Phoenix.

La fábrica Schülke fue fundada en $1851^{15}$, evento que fue amenizado con la cerveza producida por su vecino Carlos Anwandter. El empresario ${ }^{16}$ Schülke sitúa

15. Bernedo. 1999, otras referencias señalan su fundación en 1848, n. del a.

16. Al respecto, Blancpain (1974) señaló que: "Hermann Schülke, siguiendo el ejemplo de Renous en Osorno, paga 500 pesos a una docena de propietarios indígenas ficticios por la adquisición de un bosque entre Cutipai y Niebla". En el Informe de la Comisión de trabajo autónoma mapuche. El método de apropiación de tierras también es descrito por Rosales en "Recuerdos del Pasado" y por Rodulfo Philippi en 1858 de esta manera: "se colocaba a un indio en el lugar del terreno que se las viviendas en la parte elevada, dejando la zona baja para la instalación de los galpones de acopio, amasado y secado, balsas, pozos de cal, tinas de curtido y de lavado, y piscinas para tinte. El inmigrante G. Schiele, que había trabajado como aprendiz en distintas curtidurías en Alemania, Hungría y Suiza, emigró a Valdivia en 1854 y obtuvo inmediatamente una plaza de trabajo en el establecimiento de Schülke, describe los modestos inicios de esta curtiduría:

"Al tercer día después de mi llegada estaba ya trabajando en la curtiembre del señor Hermann Schülke, en Valdivia. (...) En Valdivia no existía el año 1853 más que la curtiembre del señor Schülke en pequeña escala; pues no tenía más que nueve pozos, sin contar los co-

querían apropiar para que levantara un ranchito y sembrara un pequeño papal o maizal y después se compraba al indio no solo el pequeño espacio cultivado sino miles de cuadras como de su propiedad".

Figura 6

Fachada frontal (página anterior) y fachada norte de la casa.
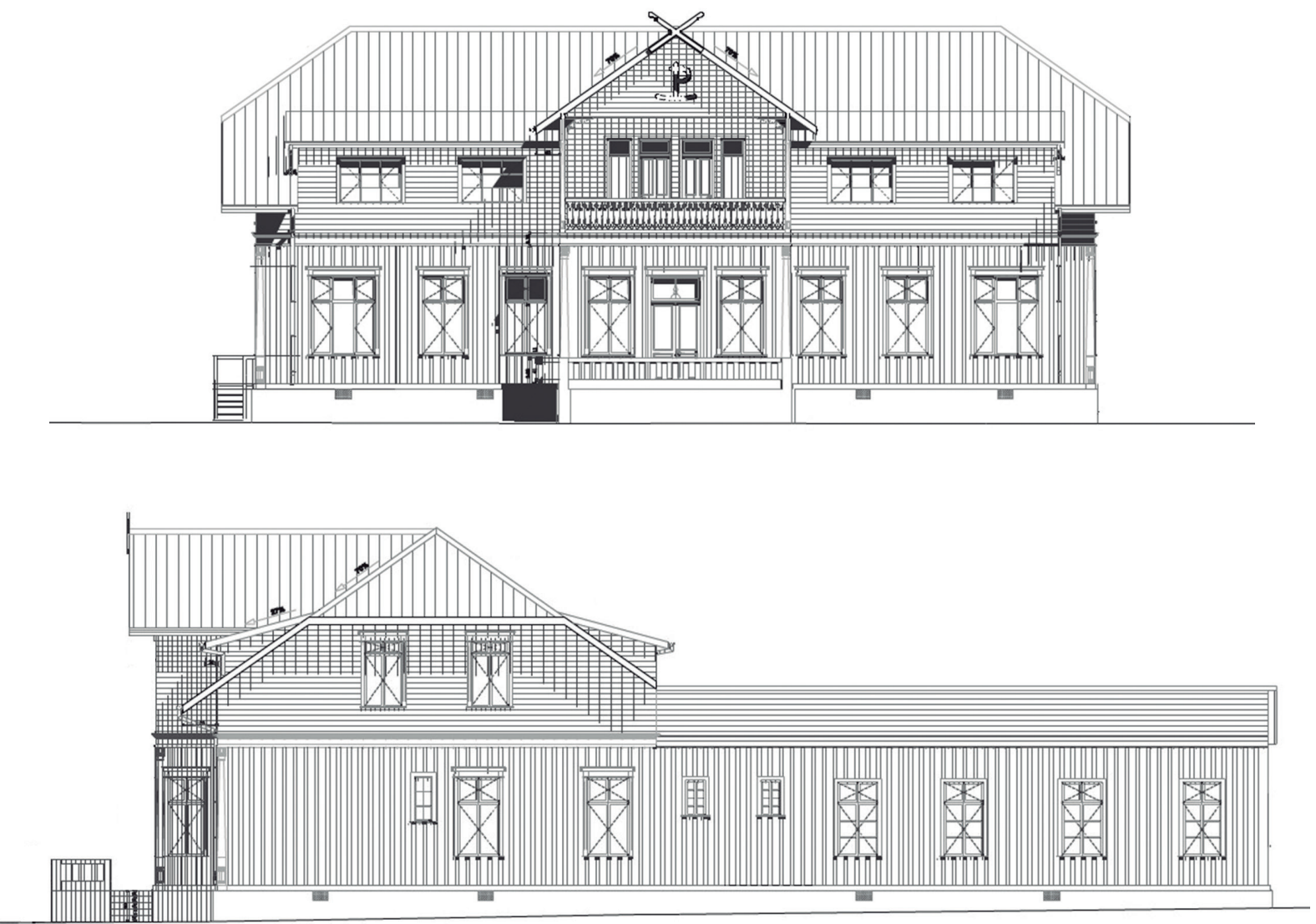
lores necesarios i tinas que sirven para el curtido. Poco a poco fue prosperando este negocio, i con los años se establecieron nuevas curtiembres hasta llegar a la importancia que hoi tienen. En el interior no había curtiembres en aquel tiempo" (Bernedo, 1999).

En 1859, Treutler señaló sobre la propiedad:

"Deslinda con esta propiedad - refiriéndose a la de Carlos Anwandter- separada de ella por jardines, una gran curtiduría, perteneciente a Herr Schülke de Brandenburgo y que también era un establecimiento de gran importancia. Comprendía de un gran edificio en la playa, detrás del cual se encontraban los talleres" (1856).

Eduardo ${ }^{17}$ Prochelle entró como socio y administrador de la curtiduría, y pasó a llamarse Schülke \& Cía. En 1878, la firma fue transformada en una sociedad anónima cerrada, llamada Compañía Industrial de Valdivia, cuya propiedad accionaria pasó mayoritariamente a manos de Prochelle y de sus hijos Carlos y Gustavo, así como de otro socio, Reinaldo Fuchslocher; posiblemente, es en el momento en el que Schülke abandona junto a su familia definitivamente el país, liquidando todos sus negocios y propiedades.

Paralela a la nueva sociedad, Prochelle incorporó dos nuevas sectores a la firma: una pequeña refinería de sal y un establecimiento de comercio para ventas a público, de grandes dimensiones, en el centro de la ciudad. Para 1880 la fábrica de cueros fue continuamente expandida, por lo que ya en 1894 consumía 15,000 quintales métricos de cáscara de lingue.

La Casa Prochelle I fue edificada en 1902 (Guarda, 1995) por Gustavo Prochelle Brummer, utilizando un procedimiento singular que mezcla elementos técnico constructivos de distintas culturas, maximizando la utilidad del material de la zona. Construido el volumen principal de dos plantas con una superfi-

17. Eduard August Ferdinand Prochelle nació en Berlín en 1828 ingresando al país como comerciante; llegó a Corral el 23 enero de 1854 en el barco hamburgués Henriette, que zarpó de Hamburgo hacia Valdivia y Valparaíso el 7 de octubre 1853 al mando del Capitán A. B. Matsen. El gobierno de Chile le asigna la chacra $\mathrm{N}^{\circ} 8$ en Llanquihue, allí se dedica a la explotación del Alerce, junto al irlandés Luis Dartnell instalaron vastos aserraderos en El Alerce o Villa los Alerces. El de Prochelle cortaba 6,000 pies por hora el de Dartnell cortaba entre 6,000 y 8,000 pies. Se comerciaba principalmente en durmientes, empezó a exportarse hacia los puertos mineros del norte y Perú: para el ferrocarril de La Oroya. Por cuatro durmientes de alerce se cambiaba un quintal de harina en Santiago y por otro se conseguía un galón de aguardiente de chancaca en Valparaíso. De Puerto Montt se trasladó a Valdivia. cie de $750 \mathrm{~m}^{2}$, más un anexo continuo de la primera planta, para cocina y servicios, y sabemos que contaba con otra extensión que generaba un patio semicerrado, donde era usual la instalación de una sala de juegos y bodega.

\section{Materialidad y construcción}

\section{Madera}

Las naves habitables de la mansión, están construidas íntegramente de madera a estilo de las edificaciones para las poblaciones insertas en el bosque templado húmedo de nuestro país. El principio tecnológico del recurso maderero ha sido comprobado desde los primeros asentamientos hasta hoy conocidos (Dillehay, 2003), con el aprovechamiento de las características físico-mecánicas de cada especie, utilizando el recurso de acuerdo con la variedad en textura, dureza y ductilidad, tanto en la estructura base como en la incorporación de elementos decorativos. La cubierta corresponde a una interpretación de tradición hispana.

Es así como encontramos en esta vivienda el uso de Nothofagus oblicua -roble- para sobrecimientos, vigas de estructura y los verticales que van conformando los muros; Laurelia sempervirens Looser, laurel- para pisos y guarda polvos; Fitzroya cupressoides, -alerce- para ventanas y puertas, el entablado exterior; Presea lingue, -lingue- para los cierres verticales exteriores y pilastras.

Los muros de la primera planta están formados por vigas dispuestas en forma vertical una al lado de otra de 25 x 13 x 384 centímetros, a 36 x 13 x 384 centímetros, estas forman el muro interior y exterior, tienen en la base una espiga que va encajada en la viga de sobrecimiento que lleva la caja. En el extremo superior tiene una caja abierta, a todo lo ancho de la pieza, que permite el encaje de una viga transversal que las traba, estas además, están cruzadas cada dos piezas, en forma alternada por tres y dos clavos de hierro de 55 centímetros de largo, de cabeza convexa, que en las juntas queda inserta en la madera de tal forma de dejar no más de 0,1 centímetros de espacio entre una y otra. Por el exterior estas uniones son tapadas por un listón de 12 por 384 centímetros de largo, con bordes acanalados y remates de medio rodón. Por el interior, tenían la misma solución que presentan las casas de origen germano, que posiblemente se implementó en las de origen de familias hispanas y mestizas y nativas, pero hasta ahora no se ha podido documentar; que son entablados de madera de laurel dispuesto en 
forma horizontal, en todos los muros perimetrales y encamisado, esta evidencia fue eliminada por los propietarios anteriores, Inmobiliaria James Bay S.A., por lo que solo se pudo rescatar alguna evidencia en los interiores, el papel de enlucido bajo los guardapolvos.

\section{Piedra}

Los cimientos se elaboraron con esquisto pelítico, siendo correspondientes litológicamente al Complejo Metamórfico de Bahía Mansa (Duhart, 2001). Se formó en el Paleozoico Temprano, por lo que es común encontrar depositaciones en los márgenes costeros marítimos. Los depósitos expuestos y laminados se encuentran desde los márgenes del río Valdivia desde el Cutipay hacia el oeste.

El material es usado desde la llegada de los españoles en la construcción de inmuebles civiles y militares, a diferencia de estos, las edificaciones asociadas a la colonización alemana no presentan canteado de los bordes, el material es seleccionado de tamaños regulares de las canteras naturales, denominando de esta forma a aquellas expuestas en los márgenes costeros y laminadas por tracción; en aquellos casos, en que hay evidencia de trabajo litológico corresponde a material reciclado o extraído de las edificaciones hispanas.

\section{Cal + arena}

Usado en el mortero, está compuesto por un conglomerado con arena y cal de escasa compactación, y para enlucido con una mezcla fina de árido y pulida.

Está construida con un sobrecimiento de piedra laja, donde no hay regularidad en el tamaño de las piezas y su disposición obedece a la nivelación de la base, ubicando las piezas en horizontal una sobre otra con hiladas irregularmente alternadas, reforzadas y enlucidas con una capa de revoco de cal y arena de 2 a 6 centímetros de espesor.

\section{Hierro galvanizado}

De ondulado ancho, la cubierta a cuatro aguas con los extremos rebajados, fue modificada entre los años 1948 y 1951 para abrir vanos hacia los frentes, usando el mismo material.

\section{Materiales incorporados en reparaciones}

Durante el periodo de funcionamiento de la casa como habitación familiar, se llevaron a cabo reparaciones en el sobrecimiento con una mezcla burda con arena de grano grueso; este fue usado para consolidar y recuperar faltantes de mortero original, para cubrir e imitar la viga de sobrecimiento. Ladrillo de masa compacta, volumen regular miden $6 \times 13 \times 28$ centímetros y de superficie lisa, se utilizó para recuperar hilada piedra, usándolos para nivelar y rellenar faltantes de piedra laja.

Las hiladas de ladrillo incorporados son para nivelar y para llenar vacíos en los faltantes de piedra o madera. Los motivos de esta intervención parecen ser dos:

asiento de la estructura de madera y deterioro de las vigas de sobrecimiento

pérdida por tracción, acción eólica y lluvia del revoco y mortero, que a su vez provoco la pérdida de piezas líticas.

La selección de maderas usadas en esta edificación corresponden a las más adecuadas para cada elemento a la que fue destinada, el Nothofagus oblicua por ejemplo, además de ser resistente a la humedad posee gran resistencia mecánica, deteriorándose solo cuando está en un medio ambiente con alta concentración de agua, o expresada como humedad relativa constante.

En el caso de los sobrecimientos de Nothofagus oblicua sometidos a la humedad permanente que escurre por los muros, y sometidos a la tracción por carga de los verticales que conforman la muralla, estas piezas por secciones fueron perdiendo su resistencia mecánica, formando grietas que paulatinamente fueron parasitados por insectos xilófagos $\mathrm{u}$ hongos de pudrición parda.

Los verticales elaborados con la misma especie, presentan los mismos síntomas asociados a las áreas donde se concentra la humedad, como las bajadas de agua, áreas poco ventiladas, principalmente sobre el muro orientado al noreste, con árboles frondosos cercanos a la fachada, y excepcionalmente en la esquina sureste.

Excluyendo las lesiones físicas mecánicas más importantes que presentan las maderas por el exterior, el resto de ellas corresponden a falta de mantención como limpieza, reparaciones mal realizadas, faltas de 
sello sobre fisuras, pintura decapada, fotoxidación, canales y bajadas de aguas rotas y mal diseñadas.

Por el interior, las lesiones más graves están estrictamente asociadas a las filtraciones de los radiadores, la higroscopicidad de la madera y la expansión de la fibras permitió la anidación de Poretormes quadricollis.

\section{Piedra}

Presenta faltantes de piezas debido a la fractura, pérdida de revoco y de mortero.

\section{Hormigón}

El revestimiento de hormigón tiene una densidad de 2 a $4 \mathrm{~cm}$, presenta fracturas de tracción y flexión en casi todo el perímetro y pérdida de material; fue retocado con cemento sobre todo en el sector de junta con la viga sobrecimiento del frontis. En superficie presenta pérdida de enlucido, suciedad hongos y musgos.

\section{Oxidación y corrosión de elementos metálicos en fachadas}

Piezas de $55 \mathrm{~cm}$ de largo se ubican traslapados encontrados para trabar tres vigas verticales que componen los muros. Los clavos presentan oxidación superficial de estabilización con el medio, algunas de las piezas presentan exposición a la intemperie constituyendo lesión para estos como para la madera, generando canales de filtración de agua de lluvia hacia el interior, si van ser conservados en sus sitios de origen.

Procedimiento en exterior, limpieza, sello con antióxido, sellar los bordes de las cabezas con masilla epoxi eliminando bordes de unión y pintura correspondiente de fachadas, esmalte.

Procedimiento en interior, algunos presentan el intercambio de iones metálicos a las células de la madera debido a la alta humedad ambiental, y al estar sometida a años de abandono; la extracción de estas piezas sería muy difícil debido a la expansión y rigidez de las fibras de contacto.

En general, se pudo observar que estos elementos metálicos se encuentran estables, y su núcleo en condiciones "normales" a estables. Es decir, presentan oxidación superficial, no hay corrosión activa, no presentan corrosión por picado y su estructura se percibe estable. Se recomienda analizar algunas de las que se extraigan del muro noreste, para su análisis por medio de rayos $\mathrm{X}$, determinando el nivel de cohesión de metal.

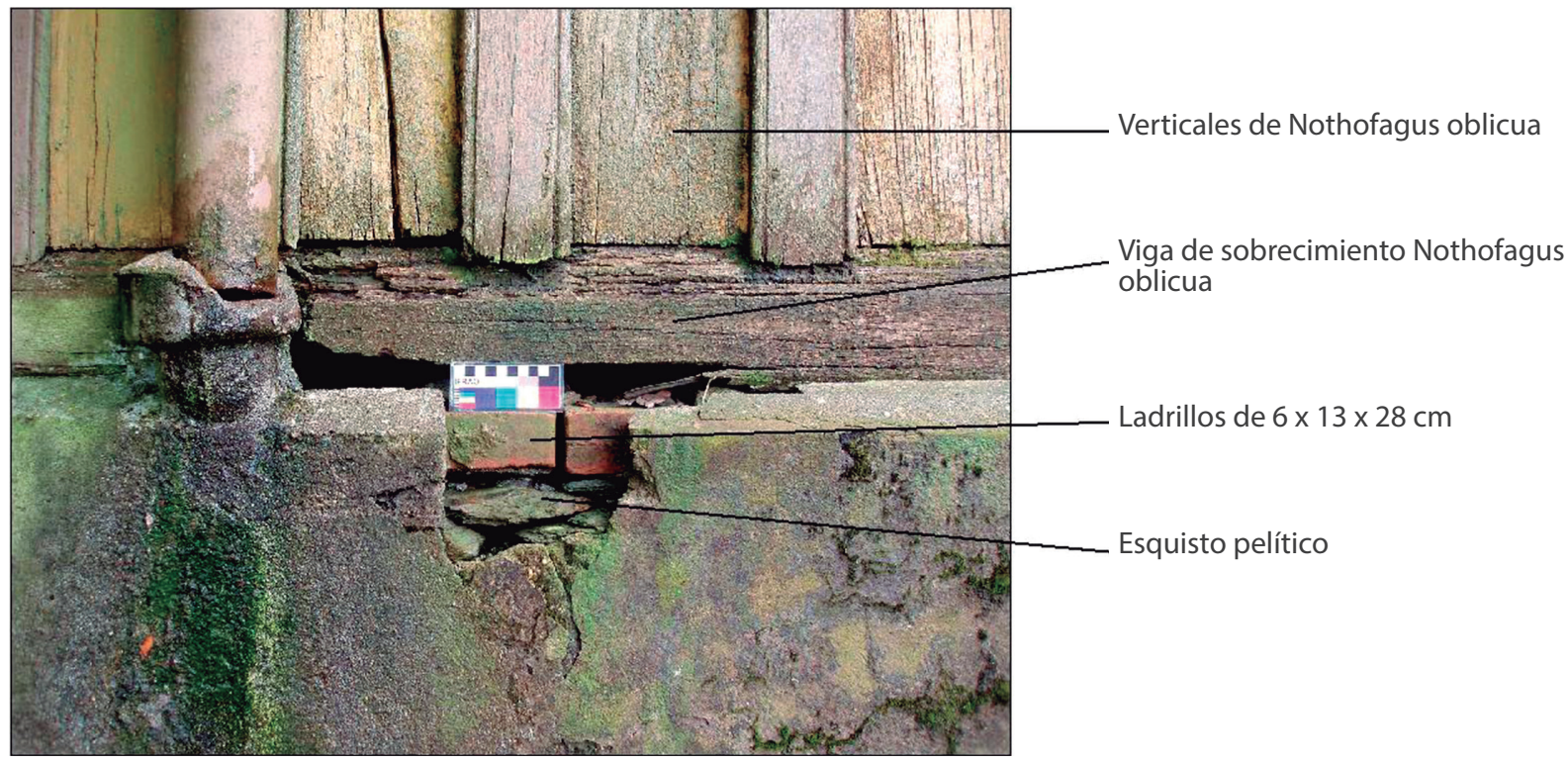




\section{Criterios de intervención}

La Casa Prochelle I es reconocida en la memoria colectiva en el emplazamiento que se ubica, junto a su par Prochelle II, conforman una de las imágenes más emblemática de la ciudad de Valdivia. Su reconocimiento y posterior protección fue un acierto (Guarda, 1995), que se ha justificado y reforzado con el sistema constructivo que presenta la vivienda, que hasta hoy se define como único en la región. Esta singularidad constructiva se define a través de la materia, por lo tanto, la técnica constructiva, como el elemento que la sustentan, son fundamentales al momento de establecer criterios para preservar esta memoria material a través del tiempo.

Como es usual en la zona, la edificación en madera es parte de la historia constructiva del sur del país, forma y materia que paulatinamente han ido diversificándose, así como las tecnologías y la disminución de los recursos madereros. Nuestra experiencia en preservación de monumentos históricos edificados en madera nativa, determina el respeto y resguardo de la materialidad original, no solo en consideración a la preservación del tangible material, sino, y funda-

Figura 8

Propuesta de soluciones sobre solera.

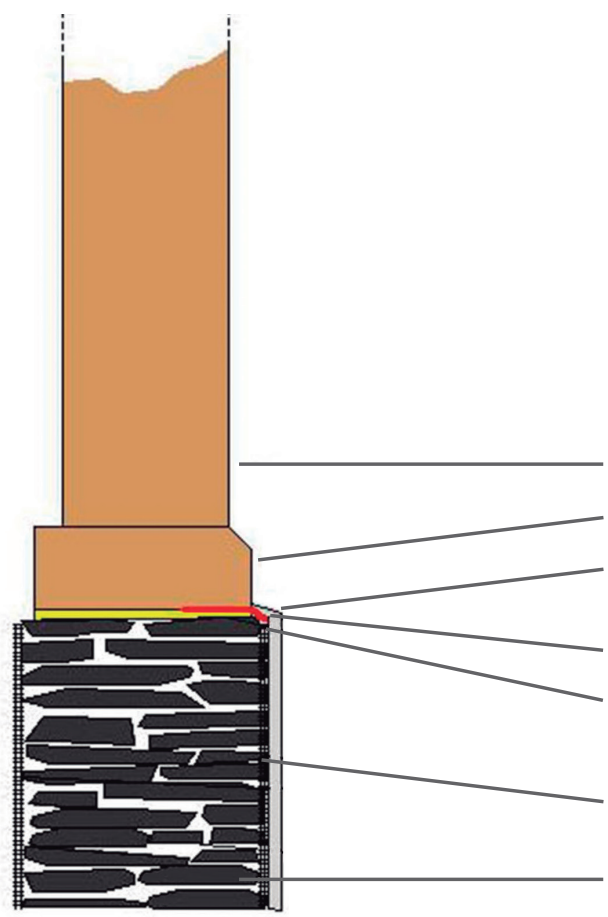

mentalmente, por el comportamiento de las especies asociadas y cómo este se estructura en la forma.

En la práctica puede existir incongruencia con criterios de intervención formal, al momento de identificar la intervención, cuando, para la intervención de una estructura en madera requiere de pulgadas, ensambles o traslapo precisos a la formulación original; cuando además, edificaciones como esta, deben ser acondicionadas para una funcionalidad que supera el uso, mucho más allá de la que tuvo en origen.

De esta forma se toma como premisa la mínima intervención, en consideración a la preservación de la materialidad original y la documentación de la intervención. Asimismo, se recomienda conservar la correspondencia material de la obra, no solo en relación a su valor intrínseco material, sino que, además, en relación a su perdurabilidad y compatibilidad físico-química del maderamen.

\section{Método y técnica para su conservación}

\section{En exterior}

El procedimiento y la técnica de las reparaciones ejecutadas, cuando la mansión estaba en uso, han
Verticales de Nothofagus oblicua

Solera de Nothofagus oblicua

Enlucido

Corta goteras de fierro galvanizado de $0.5 \mathrm{~mm}$

Fieltro alquitranado de 15 libras

Malla fibra de vidrio con Propasta E de Eurotec

Cimiento de piedra laja 
paulatinamente deteriorado la materia original contribuyendo a su desmedro estético y material, dichas soluciones deben ser eliminadas y reformuladas de acuerdo con la materialidad y procedimiento adecuados a las necesidades técnicas y estéticas de la mansión. Es importante, por tanto, recordar la compatibilidad entre materiales, considerando que la materialidad y singularidad de la casa está determinada por las estructuras envigadas que conforman la muralla, por lo que todas las actuaciones deben ir en consecuencia con su preservación, ya sea en consideración a materia original, como a la carencia, costo y complejidad en la adquisición del recurso maderable, en la actualidad y en el futuro, de piezas de este volumen.

En rigor, las intervenciones de reparación existentes deberían evaluarse de acuerdo con su precaria factura, que ponen en riesgo la materialidad original existente, por lo que conservarlo como parte del trascurrir de la edificación carece de sustento histórico-técnico. En este sentido, se justifica la recuperación del envigado de sobrecimiento original compuesto por Nothofagus oblicua con el canto botado que presentaba en origen; técnicamente, la impermeabilidad del concreto ha provocado las lesiones por humedad del envigado vertical que forman los muros.

El sobrecimiento compuesto por sillares de material lítico es otro de los elementos histórico-técnico importante de preservar así como el estuco, en primera instancia porque no hay hasta ahora, casa de este periodo o anterior que conserve los sobrecimientos en laja estucados, siendo este mismo proceso de estucado y enlucido, singular ya que la mezcla pulida en húmedo da cuenta de un proceso técnico, que ya no se usa, al menos en forma manual.

La eliminación de los sobrecimientos originales ha sido sistemática en la intervención de las edificaciones históricas en el momento de acondicionarlas para sus nuevos usos, por lo que se recomienda realizar los esfuerzos necesarios para preservar este último vestigio histórico, permitiendo con su preservación no solo la conservación de la historia constructiva y de los antecedentes materiales, que permitan en el futuro con más recursos evaluar químicamente los materiales, determinado los compuestos usados en el periodo, dando además la posibilidad de instalar una museografía el sobrecimiento, dando un valor agregado a la recuperación histórica de la casa.
Se recomienda, por tanto, eliminar el concreto que simula la solera de madera, los parches y bajadas de agua insertos en el paramento, elaborado del mismo material.

La extracción del revoco original se puede realizar en bloques aprovechando en muchos casos las fracturas, identificando el área de extracción, protegiendo la superficie con capas de papel Kraft y periódico con acetato de polivinilo (cola vinílica), el levantamiento dejara a la vista las hiladas de piedra laja permitiendo consolidar el mortero. Para su consolidación se recomienda adhesivo epoxi Protex 216, así como en el sellado del enlucido original, una vez reubicado debe ser limpiado con agua eliminando la protección de papel y pulido, rellenando las fisuras y cortes dejando a la vista la apariencia de la estructura con las huellas del paso del tiempo estables. El trabajo puede ser realizado por un albañil calificado.

El retiro del enlucido permitirá alinear y reponer material de piedra laja, consolidar el mortero, nivelar las vigas verticales y reponer la solera; se recomienda instalar fieltro alquitranado de $0.5 \mathrm{~mm}$ entre la solera repuesta y la piedra, instalar un corta goteras por el frente y reinstalar revoco con las recomendaciones antes descritas.

Las lesiones más graves en el envigado vertical que conforman los muros son los canales de desarrollo, hechos por el xilófago Poretormes quadricollis, algunas de las zonas afectadas alcanzan una altura de hasta 1.70 metros aproximadamente, los canales son paralelos dejando paredes de uno o dos milímetros entre ellas, como son fotosensibles son interiores, por lo que las lesiones no son visibles hasta que las paredes en extremo debilitadas colapsan por tracción. Una vez que la colonia ha abandonado una estructura no hay más actividad, la pieza lesionada debe cambiarse, por que no cuenta con la capacidad físico-mecánica de las no afectadas.

Es importante para su prevención eliminar del edificio las redes húmedas; si en escrito rigor hay instalación de ellas, estas deben ir aisladas del medio ambiente para evitar condensación en superficie, sobre todo si están cerca de las fuentes de celulosa.

En el caso de las piezas afectadas por Anobium punctatum por exterior, corresponden con aquellas áreas fuertemente afectadas por humedad y posteriormente por pudrición parda, ubicadas principalmente hacia el ala noreste. Las piezas colonizadas del interior pue- 


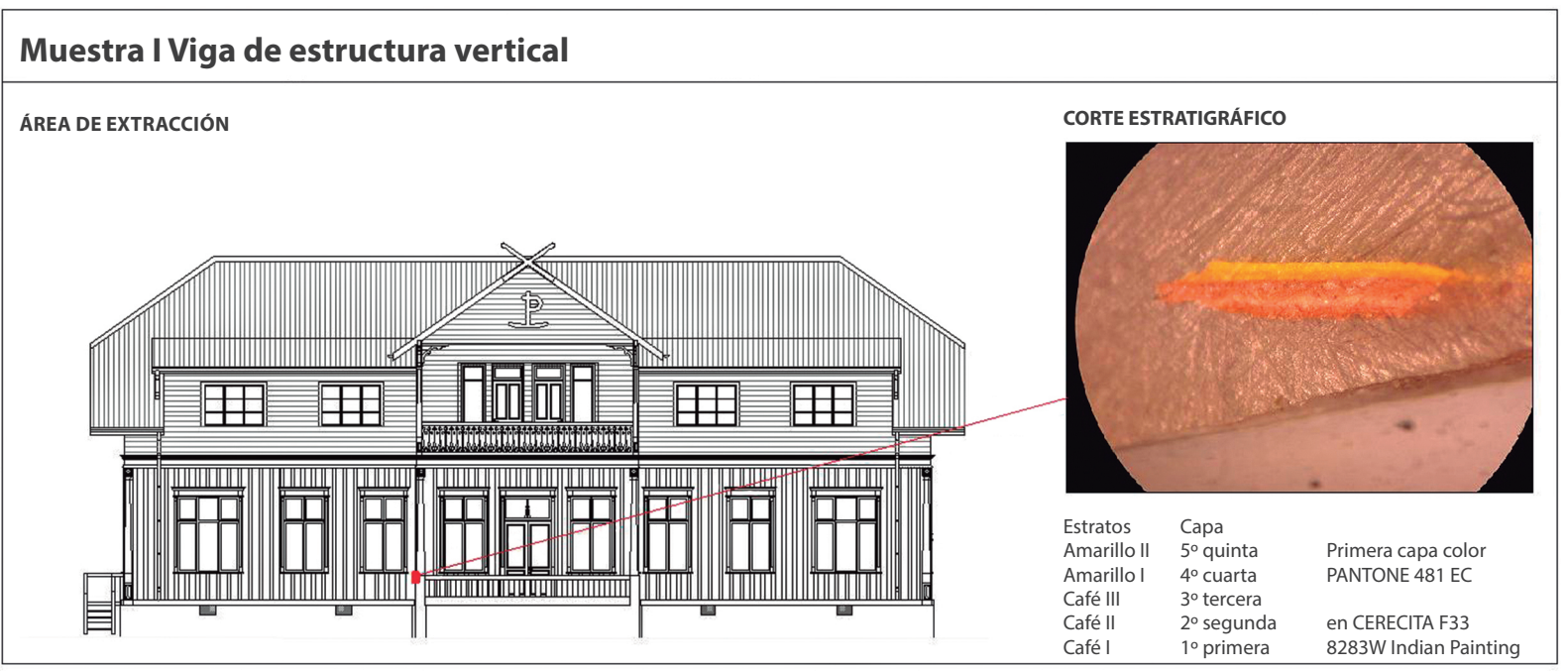

den estar activas, y estacionalmente volver a ser ocupadas en la medida que existan relieves y perforaciones para la oviposición. Las piezas con perforaciones dispersas que den cuenta de una acción esporádica y discontinua, pueden ser inyectadas con un insecticida peritroide, para aquellas que denoten áreas de actividad concentrada en tramos no significativos para la estabilidad de la pieza, se recomienda después de la inyección del insecticida, consolidar con Paraloid B72 al 5\% en butil acetato ${ }^{18}$ en la primera aplicación, aumentando la concentración en las sucesivas inyecciones hasta saturar, en ambos casos es importante, después de este tratamiento, sellar las cavidades para prevenir futuras colonizaciones con sellantes de imperfecciones para madera.

El acabado de las vigas de estructura que componen los muros debe considerar los sellos entre los verticales de cubrejunta, la superficie lisa y limpia para eliminar las posibilidades de fisuras y relieves que faciliten la oviposición y las capas de protección compuesta por pintura resistente al agua -esmalte sintético- según carta de colores a continuación.

18. Ester de baja toxicidad. Distribuido por http://www.reno. $\mathrm{cl} /$ quienes.htm, anexo ficha técnica.
Para la limpieza de fachada se recomienda realizar, idealmente entre los meses de setiembre-octubre, la aplicación de un herbicida en las zonas afectadas por musgos, el proceso debe ser llevado a cabo por una empresa especializada en fumigación y manejo de áreas verdes con experiencia. Tras una semana de la aplicación realizar dos lavados con jabón neutro, disponible en droguerías, y escobilla de cerdas sintéticas trabajando en paños de $2 \mathrm{~m}^{2}$, enjugando muy bien la superficie y dejando secar, sellando fisuras y perforaciones antes mencionadas, y lijando a mano las impurezas. No se recomienda el lavado con pistola de agua ya que solo elimina material particulado semidesprendido y agrava las lesiones que presenta la madera.

Los elementos metálicos, compuesto por la cubierta de hierro galvanizado, deber ser lavado con jabón corriente y cepillos de cerdas sintéticas cortas, proceso previo a la intervención de fachada, dos lavados y enjuagados correspondientes deberían ser suficientes para dejar la superficie libre de partículas de pintura suelta, hidrocarburos y polvo. Una vez seco, reponer clavos y sellos, la superficie posteriormente debe ser protegida con anticorrosivo Crominio de Zinc y esmalte sintético según color correspondiente, referencia anterior. 


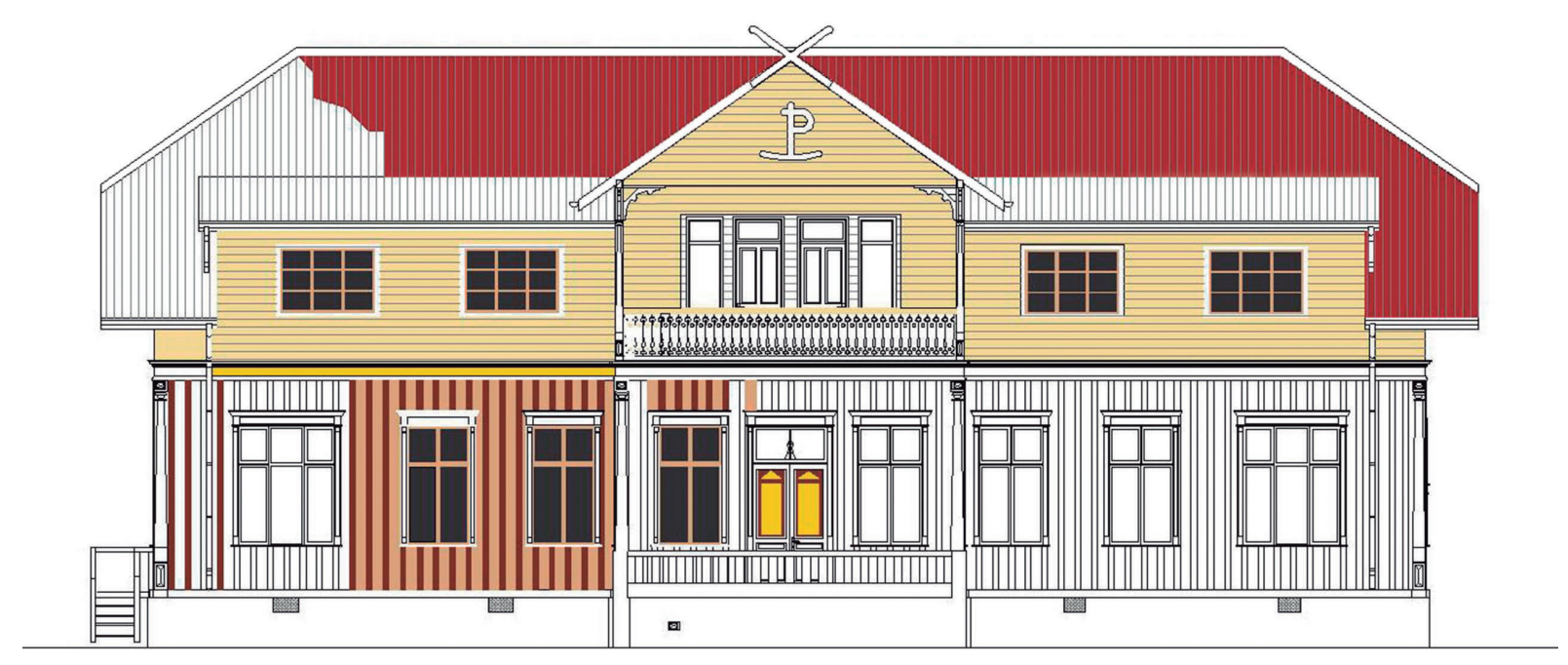

Figura 9 (página anterior)

Ficha estándar para la identificación del color.

Figura 10

Prototipo de la imagen final de la casa.

Las reparaciones en ventanas marcos, premarcos, pilastras, etc., deben ser correspondientes a la materialidad original.

\section{En interior}

En origen, las vigas verticales tenían por el interior una cubierta de sellado y revestimiento permeable a la humedad compuesto por tablones de laurel, capas de arpillera, papeles kraft o periódico y papeles murales, por lo que el agua que penetra por el exterior circula libremente por la estructura teniendo la posibilidad de migrar y evaporar por el ambiente interior. Este proceso de circulación ha permitido la preservación de los muros perimetrales evitando la pudrición o el afloramiento de hongos cromógenos, de pudrición y por coleópteros xilófagos.

Debido a que el acondicionamiento de la casa para espacio público requiere de un revestimiento incombustible, se recomienda dejar un área de ventilación de 2 pulgadas, entre el muro y la cubierta de vulcanita en todos los muros perimetrales, considerando especialmente la poca permeabilidad de este último material, evitando de esta forma la condensación en superficie, garantizando su aireación, preservación y resistencia a los agentes bióticos. Para el procedimiento, se debe contemplar no perforar las vigas que con- forman el muro por lo que se debe considerar un marco de madera que vaya apernado a suelo y cielo raso, con topes atornillados a la plancha de vulcanita, debe ser elaborada en roble pellín o laurel, es importante comprobar que la constructora use madera seca y sin nudos; en relación a este aspecto, la incorporación de maderas blandas y ácidas como el pino insigne -Pinus radiata-, u oregón y eucalipto asociadas a este tipo de edificación constituye una fuente de infestación y deterioro de las nativas, por lo que se recomienda no considerar su uso en ningún tipo de estructura permanente. En el revestimiento de vulcanita es necesario dejar cuatro entradas de aire por paño dos abajo y dos arriba, simuladas con rejillas metálicas, en paños angosto uno abajo otro arriba ubicados en diagonal. Es necesario, además, cuidar la red de instalación eléctrica instalando solo las redes de toma corriente indispensables para evitar la perforación de las vigas, principalmente de las perimetrales.

\section{Análisis de color en fachadas}

El objetivo de este análisis, es recuperar el sentido estético cromático de las edificaciones, según sus ideólogos o de su época de esplendor, se pretende además, aportar una mirada objetiva eliminando estereotipos, ya según se ha estudiado, el color en este 
caso, además de considerar la moda del momento está muy influenciado por el medio ambiente.

Este análisis se realiza ubicando en fachada las zonas menos alteradas y levantando muestras de pigmento en todas las secciones que pudieron ser recreadas con color para dar volumetría o/y destacar algunos elementos de la casa, en algunos casos cuando es posible obtener imágenes del periodo histórico la imagen en blanco y negro se puede transformar en color con este método.

El muestreo se limitó a la fachada principal, que es la que cuenta con todos los elementos decorativos y

\section{Bibliografía}

Alfonso, J. A. (1900). Un Viaje a Valdivia. La civilización alemana en Chile. Santiago de Chile: Imprenta Moderna.

Anwandter, C. (2001). Desde Hamburgo a Corral. Diario de viaje a bordo del velero Hermann. Valdivia: Universidad Austral de Chile.

Bibar, G. de (1966). Crónica y relación copiosa y verdadera de los Reynos de Chile hecha por Gerónimo de Bibar natural de Burgos MDLVIII. Santiago: Fondo Histórico y Bibliográfico José Toribio Medina.

Brouwer, H. (1926). Viaje al reino de Chile en América. Revista Chilena de historia y Geografía. Colección Churchill 111

Duhart, P. (2001). El Complejo Metamórfico Bahía Mansa en la cordillera de la Costa del centro-sur de Chile $\left(39^{\circ} 30^{\prime}-42^{\circ} 00^{\prime} \mathrm{S}\right)$ : geocronología $\mathrm{K}-\mathrm{Ar}, 40 \mathrm{Ar} / 39 \mathrm{Ar}$ y $\mathrm{U}-\mathrm{Pb}$ e implicancias en la evolución del margen sur-occidental de Gondwana. Revista Geológica de Chile, 28 (2).

Fiegelist, H. y Fiegelist, H. (2002). Genealogía de la familia Fiegelist en Suiza, Alemania, Chile y EEUU. Recuperado desde http://www.genealog.cl/Alemanes/F/ Fiegelist/Fiegelist-Chile.pdf

Guarda, G. (1993). Una ciudad chilena del Siglo XVI: Valdivia 1552-1604: urbanística, red pública, economía, sociedad. Santiago de Chile: Ediciones Universidad Católica de Chile.

Guarda, G. (2001). Nueva Historia de Valdivia. Santiago: Ediciones Universidad Católica de Chile.

Góngora Marmolejo, A. (1862). Colección Historiadores de Chile.

Irving, W. (1832). Cuentos de la Alhambra. Londres: Henry Colburn y Richard Bentley

Luebert, Federico y Pliscoff, Patricio. (2004). Clasificación de pisos de vegetación y análisis de representativi- las capas pictóricas son correspondientes al transcurrir histórico, en congruencia a un recurso preferentemente estético, muy posteriormente se incorpora a las fachadas sur y norte para unificar y como protección de la madera.

Los cortes estratigráficos muestran las distintas capas de pigmento, identificadas desde la más temprana a la más actual. El tono seleccionado, desde la visión directa de la lupa binocular, se traslada a carta normalizada CPANTONE, que corresponde en este caso, a la nomenclatura de coloración oficial de la casa y se incorpora su equivalente en marca de pintura comercial.

dad ecológica de áreas propuesta para la protección en la ecorregión valdiviana. Valdivia: WWF.

Lira, N., Diaz-Vaz, J. \& Muñoz, S. (2012). Análisis de conservación y estructura celular de la madera de seis canoas monóxilas del centro sur de Chile. Revista Magallania, 40.

Maas, C. (1949-1950). Viaje a través de las provincias australes de la república de Chile desde enero hasta junio de 1847. Revista Condor.

Mackenna, J. (1849). Sucinta descripción de la ciudad de Osorno. La Crónica. N43.

Mariño de Lobera, P. (1865). Crónica del Reino de Chile. Colección Historiadores de Chile. Tomo VI.

Millanguir, D. (2007). Panguipulli, Historia y Territorio 1850-1946. Valdivia: Imprenta Austral.

Philippi, R. (1861). Jeografia de la provincia de Valdivia, Excursión a la Laguna de Ranco, hecha en enero de 1860 por el Dr. R.A. Philippi. Anales Universidad de Chile.

Philippi, R. (1900, 15 de febrero). Revista de Chile, $\mathrm{n}^{\circ} 43$.

Schneider, G.(2010). Observaciones patolójico-terapéutico-estatísticas sobre alguna enfermedades de Valdivia. Anales de la Universidad de Chile, 0(0). Consultado el oct 2, 2013, desde http://www. anales.uchile.cl/index.php/ANUC/article/viewArticle/2420/2290

Schneider, G.(2010). Sobre la hijiene de Valdivia, por el doctor Don Germán Schneider, el día 10 de julio de 1853. Anales de la Universidad de Chile, 0(0). Consultado el oct 2, 2013, desde http://www. anales.uchile.cl/index.php/ANUC/article/viewArticle/2635/2541

Tornero, S. (1872). Chile Ilustrado, Guía descriptivo del territorio de Chile.

Treutler, P. (1958). Andanzas de un alemán en Chile 18511863. Santiago de Chile: Editorial del Pacífico. 